\title{
Molecular evidence for a diverse green algal community growing in the hair of sloths and a specific association with Trichophilus welckeri (Chlorophyta, Ulvophyceae)
}

\author{
Milla Suutari ${ }^{1}$, Markus Majaneva ${ }^{2}$, David P Fewer ${ }^{3}$, Bryson Voirin ${ }^{4}$, Annette Aiello ${ }^{5}$, Thomas Friedl ${ }^{6}$, \\ Adriano G Chiarello ${ }^{7}$, Jaanika Blomster ${ }^{1 *}$
}

\begin{abstract}
Background: Sloths are slow-moving arboreal mammals inhabiting tropical rainforests in Central and South America. The six living species of sloths are occasionally reported to display a greenish discoloration of their pelage. Trichophilus welckeri, a green algal species first described more than a century ago, is widely believed to discolor the animals fur and provide the sloth with effective camouflage. However, this phenomenon has not been explored in any detail and there is little evidence to substantiate this widely held opinion.

Results: Here we investigate the genetic diversity of the eukaryotic community present in fur of all six extant species of sloth. Analysis of 71 sloth hair samples yielding 426 partial 18S rRNA gene sequences demonstrates a diverse eukaryotic microbial assemblage. Phylogenetic analysis reveals that sloth fur hosts a number of green algal species and suggests that acquisition of these organisms from the surrounding rainforest plays an important role in the discoloration of sloth fur. However, an alga corresponding to the morphological description of Trichophilus welckeri was found to be frequent and abundant on sloth fur. Phylogenetic analysis demonstrated the retention of this alga on the fur of sloths independent of geographic location.

Conclusions: These results demonstrate a unique diverse microbial eukaryotic community in the fur of sloths from Central and South America. Our analysis streghtens the case for symbiosis between sloths and Trichophilus welckeri.
\end{abstract}

\section{Background}

The extant sloths comprise six species of medium-sized slow-moving mammals of Central and South America. They are represented by two distantly related genera Bradypus, three-toed sloths, and Choloepus, two-toed sloths. The genus Bradypus has four extant species: Bradypus variegatus, $B$. tridactylus, $B$. torquatus and $B$. pygmaeus. Bradypus variegatus, the brown-throated sloth, is the most widespread species and inhabits Central and Southern American rainforests, whereas B. tridactylus, the pale-throated sloth, is restricted to northern South America. Bradypus torquatus, the maned three-toed sloth, occupies a diminishing area of

\footnotetext{
* Correspondence: jaanika.blomster@helsinki.fi
'Department of Environmental Sciences, P.O.Box 65, FIN-00014, University of

* Correspondence: jaanika.blomster@helsinki.fi
'Department of Environmental Sciences, P.O.Box 65, FIN-00014, University of Helsinki, Helsinki, Finland
}

C 2010 Suutari et al; licensee BioMed Central Ltd. This is an Open Access article distributed under the terms of the Creative Commons Attribution License (http://creativecommons.org/licenses/by/2.0), which permits unrestricted use, distribution, and reproduction in any medium, provided the original work is properly cited. pygmy three-toed sloth, only recently described, is endemic to the small island, Isla Escudo de Veraguas on the Atlantic coast of Panama [1]. The genus Choloepus is represented by two living species: Choloepus hoffmanni, the Hoffmann's two-toed sloth, and C. didactylus, the southern two-toed sloth. Choloepus hoffmanni occurs in Central America, and in South America close to the equator, and $C$. didactylus is restricted to northern South America [2].

Sloth hair is long and coarse and that of two-toed sloths is unique in having a number of deep grooves running the length of each hair, whereas three-toed sloth hair has irregular transverse cracks that increase in number and size with age $[3,4]$. A wide variety of organisms have been reported to occur in the grooves and cracks of sloth hair, including cyanobacteria and 
diatoms; and among their fur, moths, beetles, cockroaches and roundworms [5-7]. However, the greenish color of the hair, which is most evident in three-toed sloths, is due to green algae, which in most cases have been identified as Trichophilus welckeri [6,8-10]. It is a popular assumption that the association between the three-toed sloth and the alga embedded in its hairs is a symbiotic relationship with the alga obtaining shelter in the cracks of the hair while providing green camouflage for the sloth. It also has been proposed that the alga offers no benefit to the sloth, but is able to survive in the hair because the sloth does not prevent the alga growing [3]. The hair of the three-toed sloth absorbs water like a sponge, perhaps making it an even more ideal habitat for algae, and prompting speculations that the sloth perhaps receives nutrients from the alga via diffusion along the spongy outer portion of the hairs, followed by absorption into the skin [3]. The algae growing on sloth hair may also produce exopolymeric substances that may give the hair a desired texture or allow beneficial bacteria to grow. Karsten et al. [11] found UV-absorbing mycosporine-like amino acid (324 nm-MAA) from a green alga found in sloth hair. Reduced exposure to UV-light could also be seen as beneficial to the sloth over the long run. However, there is no clear evidence supporting any hypothesis at present.

Here we collected 71 sloth hair samples from all six extant sloth species as well as 12 environmental samples from tree trunks to survey the diversity of eukaryotic organisms present there. We found evidence for the acquisition of green algae from the environment as well as retention of green algae in the hair independent of the sloths geographic location.

\section{Results}

Hair samples were examined from 71 sloth individuals, which originated from French Guiana, Panama, Costa Rica and Brazil (Fig. 1). Clone libraries were constructed and 426 eukaryotic $18 \mathrm{~S}$ rRNA gene sequences were obtained from a total of 72 taxa (Table 1). The number of eukaryotic taxa per sample varied between 12 and 22, except in $C$. didactylus where the only two sequences recovered turned out to represent the same taxon (Table 1). The estimated total number of taxa $\left(\mathrm{S}_{\mathrm{Chao} 1}\right.$ at the $97 \%$ similarity) varied between 21 and 38 being 146 for the total dataset. The Shannon diversity index with 95\% confidence intervals was equal in the sloth species containing a minimum of 12 taxa. The Shannon diversity index for the total dataset was 3.1. The coverage, which estimates whether the clone library reflects the actual diversity in the samples, was $89.3 \%$ for the complete dataset. In the comparison of different geographical areas the highest number of taxa was found on Isla Escudo de Veraguas, Panama, where the number of taxa was 22 and the estimated number of taxa was 38 (Table 2). The Shannon diversity was lower in Costa Rica $(1.4 \pm 0.3)$ and Paulo Seike Fragment $(1.5 \pm 0.4)$ than in other areas (ranging from $1.7 \pm 0.3$ to $2.2 \pm 0.5$ ). More than half of the taxa consisted of ciliates, apicomplexans and dinoflagellates (Fig. 2a). One third of the sequences were green algae. Fungi also were present in larger numbers and in addition a few 18S rRNA gene sequences from arthropods, Euglenozoa and red algae, were found. $10 \%$ of sequences could not be attributed to a known eukaryote (Fig. 2a).

PCO analysis of all eukaryotic 18S rRNA gene sequences from the sloth hair grouped most samples together, excluding the Naos and Augusto Ruschi samples and the Barro Colorado Island Bradypus variegatus -samples (Fig. 3a). The first two PCO axes explained $40.6 \%$ of the variability. However, the canonical analysis of the three species of sloths that had been sampled from several locations showed a separation of the different sloth species with squared canonical correlations of $\delta^{2}{ }_{1}=0.778$ and $\delta^{2}{ }_{2}=0.649$ (Fig. 3b). The canonical test statistic $\left(t_{2}\right)$ was significant $(P=0.007$ with 9999 permutations). The CAP program determined the optimum amount $(m)$ of principal coordinates for the canonical analysis to be 3 , which achieved maximum proportion of correct allocations (75\%) and which explained $65.8 \%$ of the variability. Correlations of taxa with both CAP axes are shown graphically in Fig. 3c. We did not include in the figure any taxa with correlations to both axes $<0.20$ nor ones which occurred only once. The analysis showed that C. hoffmanni, B. torquatus and B. variegatus harbour different taxa in their hair (Fig. 3c). Due to small amount of data from dry season we could not test the separation of samples in relation to dry and wet season. However, Naos Island C. hoffmanni and over half of Barro Colorado B. variegatus sequences were collected on dry season and the position of those samples in PCO indicates some degree of separation.

Fifty-two of the 71 sloth hair samples studied contained green algae, as observed either directly due to the greenish color of the hair, or by using light microscopy, which in some cases revealed algae even if the color of the hair was dark but not green. Green algal sequences were obtained successfully from 27 of the 71 samples. We were not able to get a PCR product for the remaining 25 samples that contained visible green algae. Green algal $18 \mathrm{~S}$ rRNA gene sequences were obtained from five extant sloth species. Despite all efforts no green algal $18 \mathrm{~S}$ rRNA gene sequences were obtained from the two hair samples of Choloepus didactylus. Green algae were neither found in microscopic examinations of these two samples. An average of $27 \%$ of the sloth samples for which $18 \mathrm{~S}$ rRNA gene clone libraries were constructed contained green algae (Fig. 2a). 


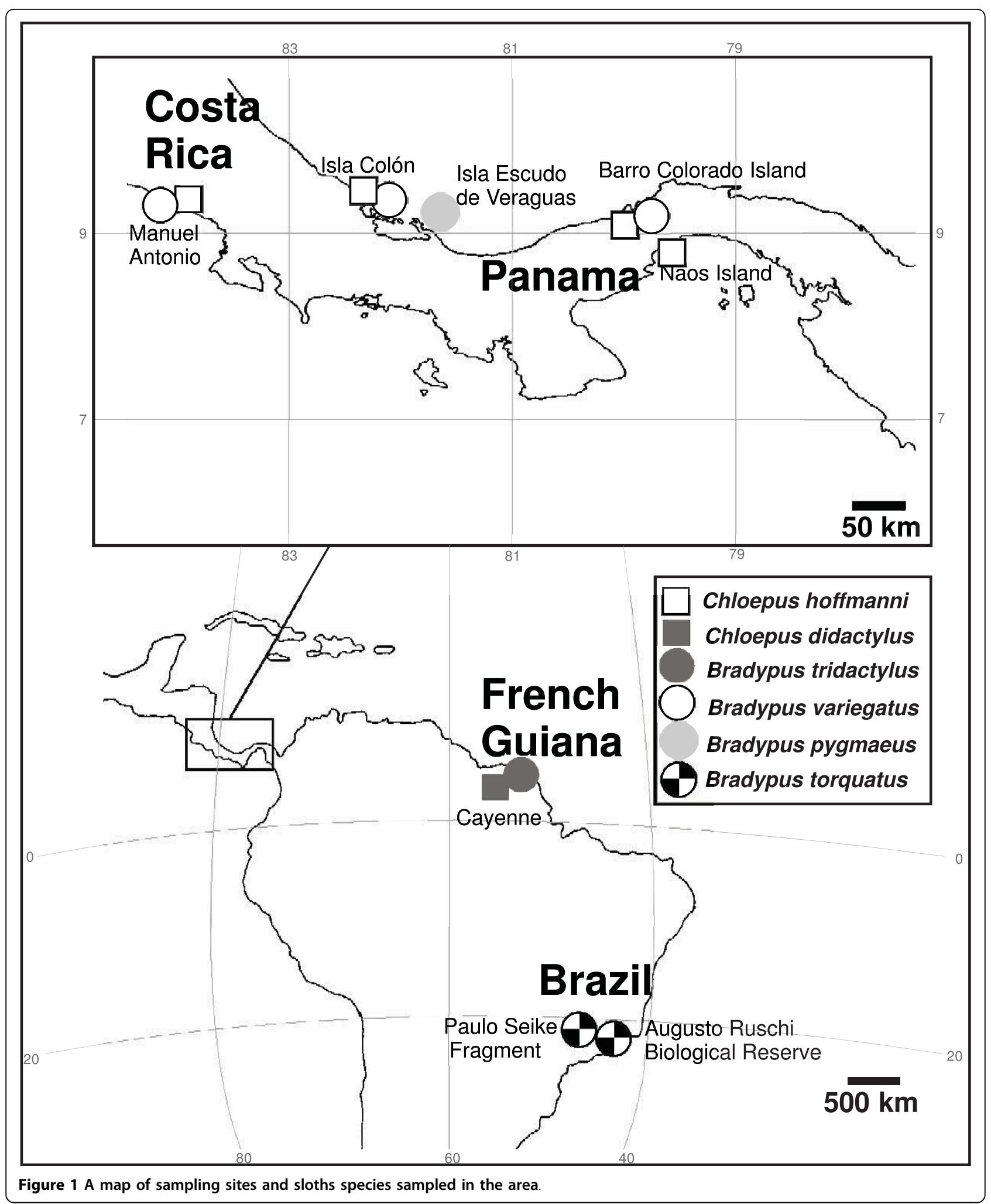


Table 1 Parameters for eukaryotic sequences according to source sloth species.*

\begin{tabular}{|c|c|c|c|c|c|}
\hline Species & Sequences & Number of taxa & Coverage (\%) & Estimated $\mathrm{n}$ of taxa $\left(\mathrm{S}_{\mathrm{Chao1}}\right)$ & Shannon diversity index \\
\hline C. hoffmanni & 116 & 21 & 89.7 & 37 & $2.1 \pm 0.2$ \\
\hline C. didactylus & 2 & 1 & $-{ }^{a}$ & 1 & 0 \\
\hline B. tridactylus & 33 & 12 & 78.8 & 33 & $2.2 \pm 0.3$ \\
\hline B. variegatus & 63 & 14 & 88.9 & 21 & $2.0 \pm 0.3$ \\
\hline B. pygmaeus & 111 & 22 & 89.2 & 38 & $2.2 \pm 0.2$ \\
\hline B. torquatus & 58 & 20 & 81.0 & 26 & $2.1 \pm 0.4$ \\
\hline Total & 383 & 72 & 89.3 & 146 & $3.11 \pm 0.15$ \\
\hline
\end{tabular}

*The number of taxa, estimated number of taxa and the Shannon diversity index from each sloth species. Shannon index values include the $95 \%$ confidence intervals. Coverage estimates if the clone library reflects the actual diversity in the samples. A taxon is defined here as having greater than $97 \%$ similarity. ${ }^{a}$ Coverage not calculated for $C$. didactylus due to the low number of sequences.

Table 2 Parameters for eukaryotic sequences according to collection site.*

\begin{tabular}{|c|c|c|c|c|c|}
\hline Collection location & Sequences & Number of taxa & Coverage $(\%)$ & Estimated $\mathrm{n}$ of taxa $\left(\mathrm{S}_{\text {Chao1 } 1}\right)$ & Shannon diversity index \\
\hline Naos Island, Panama & 18 & 10 & 55.6 & 38 & $2.0 \pm 0.5$ \\
\hline Barro Colorado Island, Panama & 37 & 10 & 83.8 & 17 & $1.7 \pm 0.3$ \\
\hline Isla Colón, Panama & 90 & 15 & 93.3 & 20 & $2.1 \pm 0.2$ \\
\hline $\begin{array}{l}\text { Isla Escudo de Veraguas, } \\
\text { Panama }\end{array}$ & 111 & 22 & 89.2 & 38 & $2.2 \pm 0.2$ \\
\hline Manuel Antonio, Costa & 34 & 6 & 94.1 & 7 & $1.4 \pm 0.3$ \\
\hline Rica & & & & & \\
\hline Cayenne, French Guiana & 35 & 12 & 82.9 & 27 & $2.2 \pm 0.3$ \\
\hline Augusto Ruschi, Brazil & 24 & 12 & 66.7 & 19 & $2.0 \pm 0.5$ \\
\hline $\begin{array}{l}\text { Paulo Seike Fragment, } \\
\text { Brazil }\end{array}$ & 34 & 10 & 85.3 & 12 & $1.5 \pm 0.4$ \\
\hline Total & 383 & 72 & 89.3 & 146 & $3.11 \pm 0.15$ \\
\hline
\end{tabular}

*The number of taxa (with $97 \%$ similarity), estimated number of taxa and the Shannon diversity index from each study area. Shannon index values include the $95 \%$ confidence intervals.

The majority of the green algal sequences obtained from the hair samples formed a clade of their own within the green algal class Ulvophyceae, distinct from other publicly available taxa. This group received high support (100\%) for its monophyly in all phylogenetic analyses that were employed (Fig. 4). Based on the morphological characters, small $(3-13 \mu \mathrm{m})$ thick-walled cells without pyrenoids (Fig. 5), the clade is likely to correspond to the green algal genus Trichophilus, which has been described by Weber-van Bosse in 1887 [8,12]. Interestingly, there were no other green algal species found in the same hair samples in which Trichophilus was found. The clade was subdivided into three subclades that received moderate to high internal node support. Two clades, A and C in (Fig. 4) were formed by rRNA gene clones originating from Choloepus hoffmannii hair samples. Clones in the clade B originated from the hair of Bradypus. Within clade B, the sequences from $B$. tridactylus were different from those of other Bradypus species; there were four synapomorphic positions at the 5'-end of the 18S rRNA gene that distinguished the $B$. tridactylus hair alga from the corresponding alga of other Bradypus species. The bootstrap values for the clade $\mathrm{B}$, originating from hair samples of Bradypus, was high (99-100\%) in MP, NJ, GarliML analyses and 69\% in ME analyses (Fig. 4). Clades A and C, which originated from Choloepus, were also supported by high bootstrap support (clade A: 7399\%, clade B: 95-100\%, Fig. 4). Separately from the Ulvophycean green algal clade, green algae from sloth hair grouped with several Trentepohlia-species, including Trentepohlia annulata, as well as with Prinzina lagenifera, Myrmecia sp., Asterochloris sp. and Chlorella-like algae. The bootstrap supports for these clades were up to $100 \%$. These samples all came from Bradypus torquatus from Brazil and Choloepus hoffmanni from Panama. One of the Brazilian samples, BT53, contained two taxa that clearly grouped separately in the phylogenies (Printzina and Myrmecia; Fig. 4).

We obtained 78 sequences from the 12 environmental samples from Barro Colorado Island. Half of the sequences were green algal or from higher plants. Fungi were also abundant and $10 \%$ of sequences were from ciliates and other alveolites (Fig. 2b). All green algal sequences from tree bark were attributable to the genus Trentepohlia, a terrestrial green algal genus occurring 


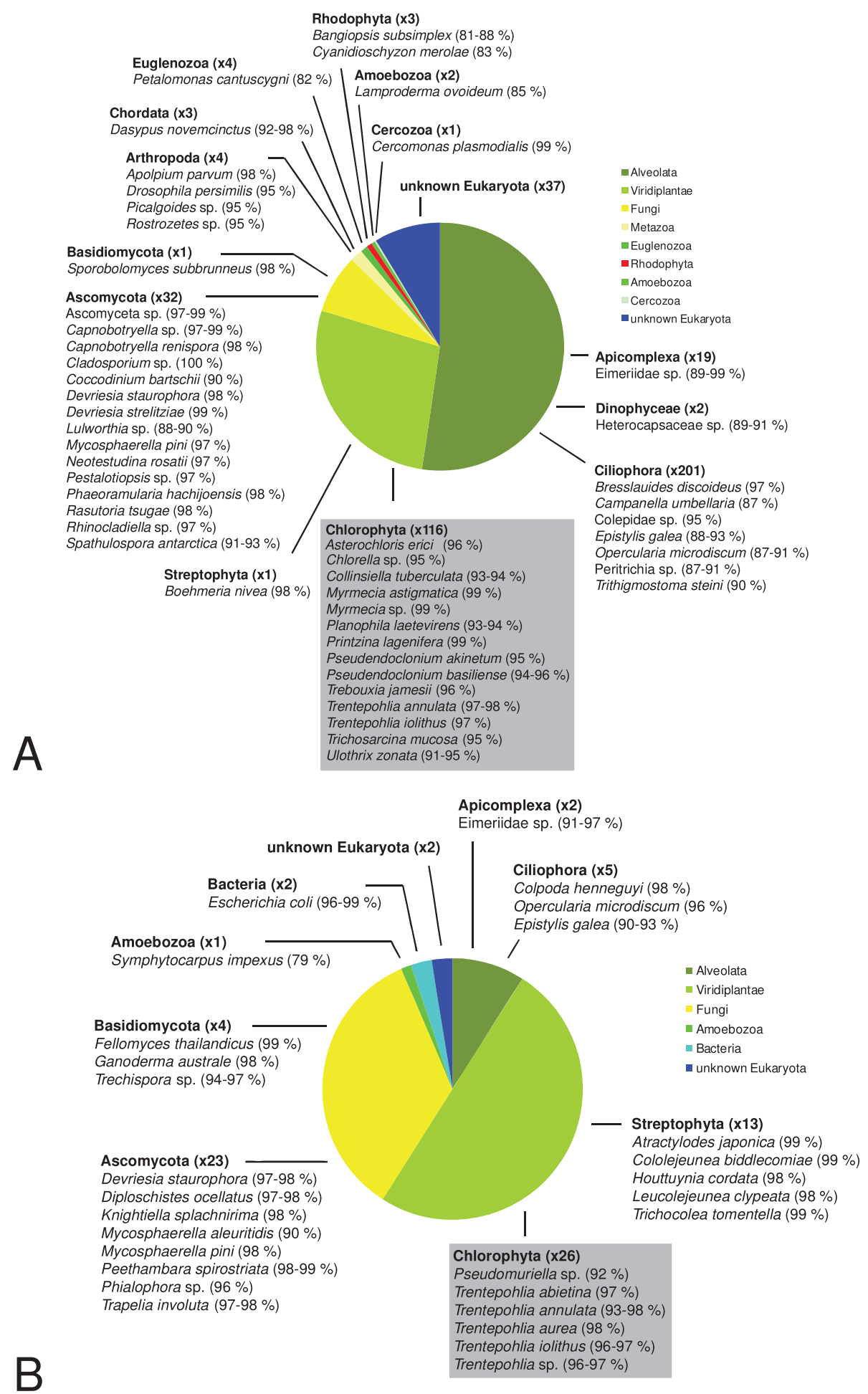

Figure 2 Diversity of all eukaryotic taxa sequenced from sloth samples. (A) Diversity of eukaryotic taxa sequenced from all samples (B) Diversity of eukaryotic taxa sequenced from environmental samples collected from Barro Colorado Island, Panama. Taxa names were assigned to the closest known matches in GenBank and it is possible that they represent undescribed or unsequenced species related to the taxa listed in GenBank. Percentage of similarity is given after each taxon name. 


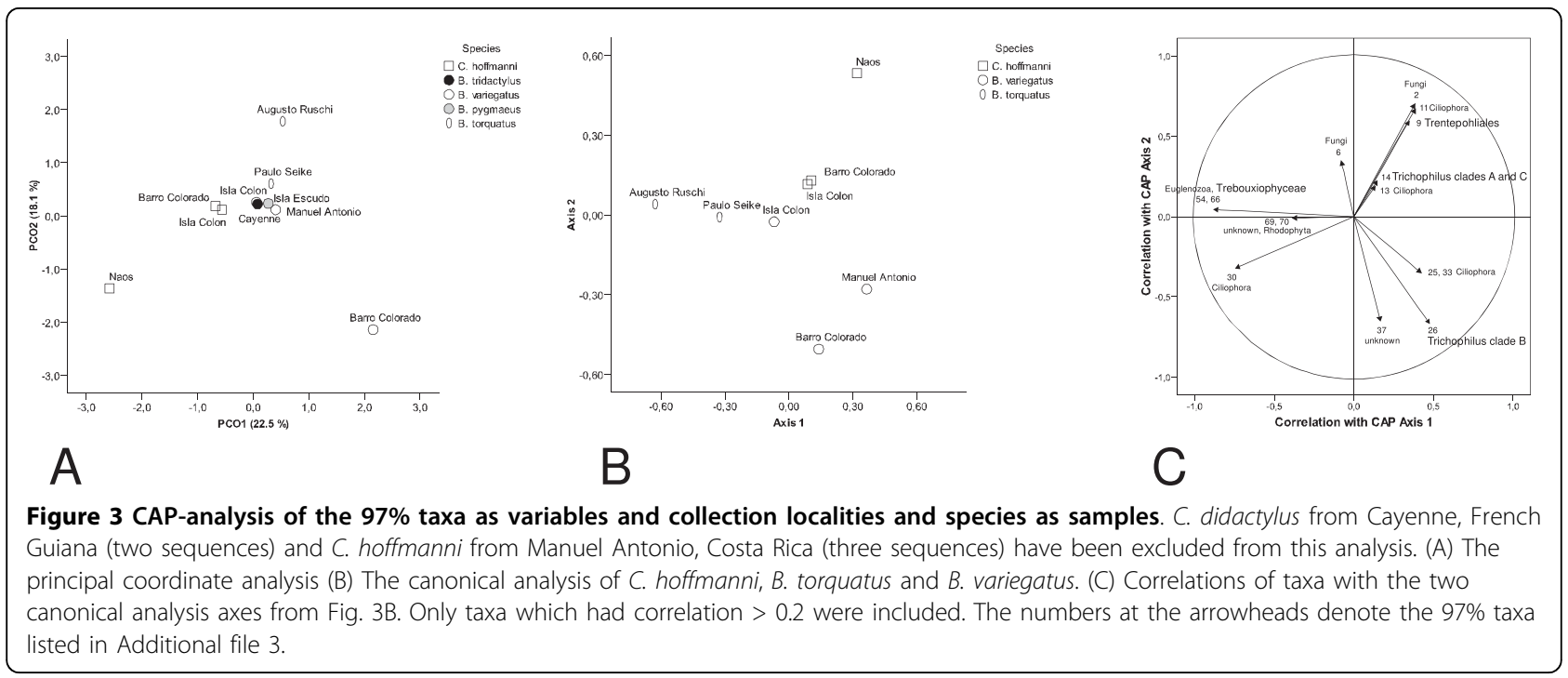

both in temperate regions as well as in tropics. They formed several independent lineages within the Trentepohliales clade of the 18S rRNA gene phylogeny (Fig. 4).

\section{Discussion}

22We found evidence for three different patterns of algae that occur in the hair of five sloth species: 1) The green alga in the fur of the brown-throated sloth, $\mathrm{Bra}$ dypus variegatus, and the pygmy three-toed sloth, $B$. pygmaeus, is a unique species and no other green algal species were found in their fur. Microscopy of the alga on the hair revealed characteristic features to the description of Trichophilus (Weber-van Bosse 1887), which has indeed been described from the hair of $\mathrm{Bra}$ dypus. 2) The maned three-toed sloth Bradypus torquatus was shown in our study to host a variety of algae belonging to genera known to be terrestrial, e.g. Trentepholia and Myrmecia. 3) The Hoffmann's twotoed sloth Choloepus hoffmanni and the pale-throated sloth Bradypus tridactylus, showed both patterns; they hosted terrestrial green algae from their surroundings, as well as the unique genus Trichophilus.

The green alga Trichophilus that was found in B. variegatus, B. pygmaeus and B. tridactylus was separated in the phylogenetic trees from the Trichophilus occurring in C. hoffmanni. The Bradypus-clade was supported by high bootstrap values and as Bradypus variegatus and Choloepus hoffmanni inhabit the same geographic area and habitat [13], the separation of Trichophilus inhabiting Bradypus suggests co-evolution between Trichophilus and Bradypus species. This is further supported by the cell sizes of Trichophilus in Bradypus and Trichophilus in Choloepus being different.
Trichophilus welckeri [8] has been described from sloth hair and generally has been thought to be the only green alga infesting sloth hair [6,9-11]. However, in former phylogenetic studies $[10,11] T$. welckeri (strain SAG 84.81) was shown to group with Prasiolopsis ramosa, which is contrary to our study. We suspect earlier studies to be erroneous species identification, made because of its habitat and the morphological investigation of the strain supports this. The strain SAG 84.81 resembles Prasiolopsis by forming irregular cushion-like tufts of pseudoparanchymatous filaments and cells with single, stellate, pyrenoid-containing chloroplast typical of the Prasiolales [10] rather than numerous small, discoid chloroplasts without pyrenoids described for Trichophilus [12]. Therefore our understanding is that Trichophilus welckeri has been found previously in nature $[6,8,9,14]$ but has not yet been isolated into pure culture and sequenced before. It is likely not to occur in any other environment besides sloth hair given that tropical terrestrial green algal species like $T$. welckeri have not been found before. Its restricted occurrence may be explained by it being host-specific and possibly thermophilic.

Among all 71 sloth individuals studied, $73 \%$ hosted algae in their fur. It was either observed by the greenish color of the fur or seen under the microscope in closer observation. Seven of the 19 individuals in which we found no evidence of algae were babies still at the age of clinging to their mothers suggesting that at least Trichophilus is gained in childhood, most likely from the mother. This observation is supported by an earlier study noting that sloths gain the algae and other parasites by the time they are a few weeks old [5]. Besides 


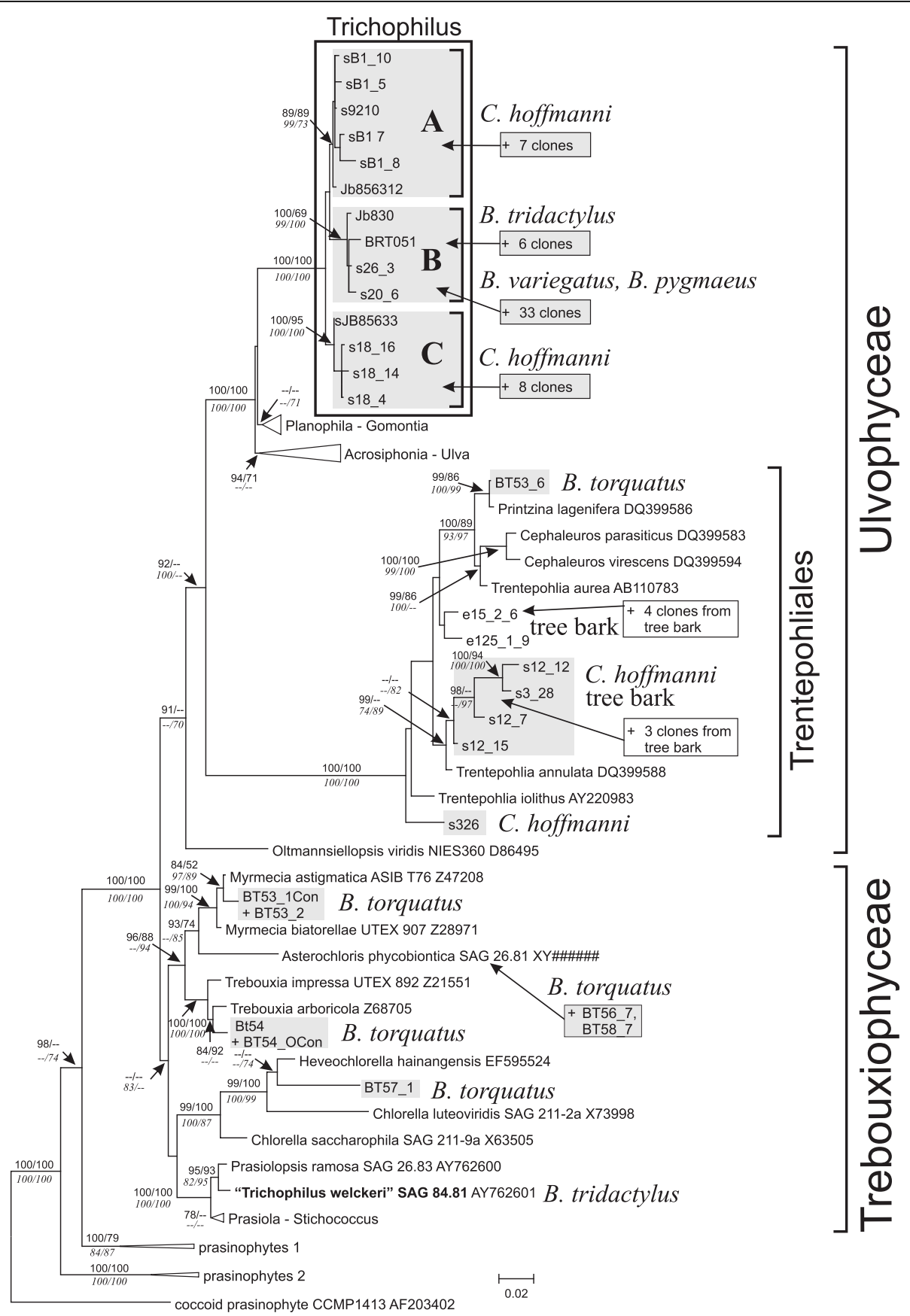

Figure 4 Phylogenetic tree of the green algae growing on sloth hair. Maximum likelihood (ML) phylogenetic analysis of $18 \mathrm{~S}$ rRNA gene clones representing green algae growing on the hair of five species of sloths (highlighted in grey) and bark of tropical trees, their next closest relatives from the classes Ulvophyceae and Trebouxiophyceae and five species of prasinophytes. The phylogeny shows the best ML tree inferred using the programme GARLI v0.96. Numbers at internal branches are bootstrap values (> 65\%; from MP and ME analyses above lines, from NJ and GARLI ML below lines) and are given only at those internal nodes which were also resolved by PAUP ML and Bayesian analyses (with posterior probabilities $>0.95$ ). The strain previously assumed to represent the sloths hair alga, Trichophilus welckeri, is marked in bold. Sequences except those where accession numbers are given are reported for the first time in this study. Clones whose phylogenetic positions have been inferred by adding their sequences to this ML phylogeny in ARB (see text) but which were not used to construct the phylogeny were simply added to the figure (marked by "+"). Additional rRNA gene clones from sloth hair samples and tree bark that were positioned into clades A-C and the Trentepohliales, respectively are listed in Additional file 4. Some branches were compressed into triangles for clarity of the graphic, the sequences which they contain are listed in Additional file 5. 


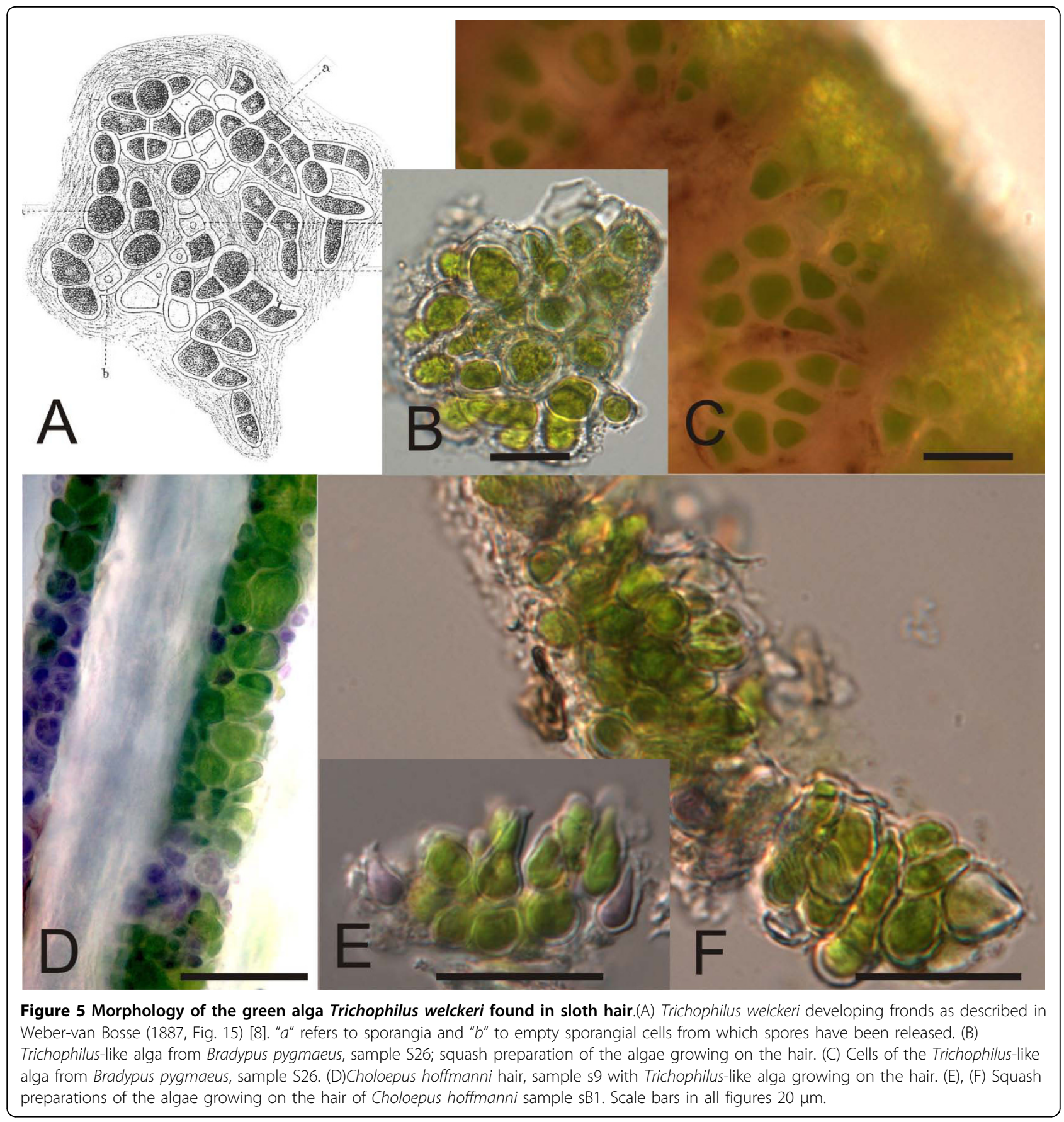

Trichophilus, other green algae found in sloth hair were terrestrial Trentepohlia, Prinzina, Myrmecia and Trebouxia -species as well as Chlorella-like algae. Among these, only Trentepohlia has been reported previously from sloth hair [6]. It is possible that sloths gain these algae from the environment and host them in their fur. However, they may also represent sloth-inhabiting specialists at a finer evolutionary level, e.g. species level, than Trichophilus does. That there were 25 hair samples containing visible green algae but for which we were unable to get PCR-product, suggest that there were either too few algae in the sample or there were PCR inhibitors present in the DNA extracts. This problem could be overcome by culturing the microbial community from fresh hair samples. The diversity of other eukaryotic organisms in the hair was high, as expected, based on previous studies, which have observed a wide range of animals, e.g. moths, beetles, cockroaches, and roundworms [5]. However, a surprising number and diversity of ciliates and fungi were also found in the hair 
of all sloth species, excluding $C$. didactylus, for which only two sequences were analyzed. All geographical areas studied, except Costa Rica, had similar levels of eukaryote diversity. The similar diversity is likely to be explained by the similar habitat of sloths, regardless of the geographical area they inhabit. However, regardless of the similar diversity, the species composition of eukaryotic organisms varied as was seen in the PCO and CAP-analyses (Fig. 3). The eukaryotes in B. variegatus, B. torquatus and C. hoffmanni were different (Fig. 3). Partly this separation can be explained by the differing green algae inhabiting the hair as was seen in the phylogenetic tree in which Trichophilus in Bradypus was separated from Trichophilus in Choloepus (Fig. 4). Similarly, ciliates were different on the three compared species. This can be due to differing hair structure and possibly chemistry as well as differing ecology of the species. It may also reflect the divergence of the two sloth genera about 20 million years ago [15], which may have led to the separation of the cohabiting eukaryotes as well.

The species composition of Naos Island C. hoffmanni was clearly different from other Choloepus samples from Panama. This may be due to the environment where the sloths are living and the fact that samples were collected on dry season. Naos Island is a small and dry island on the Pacific coast of Panama, receiving on average 1800 $\mathrm{mm}$ rainfall per year [16]. Barro Colorado Island and Isla Colón, are located closer to the Atlantic coast of Panama, and therefore are moister, receiving rainfall of 2600-3300 mm per year [16].

The difference in the species composition in Barro Colorado Island Choloepus and Bradypus was striking (Fig. 3a) as the samples were collected from the same area, although the majority of Bradypus sequences were obtained from sloths on dry season. In contrary, Choloepus and Bradypus samples from Isla Colón were collected from the same area both on wet season being close to each other in the PCO-analyses (Fig. 3a). This suggests that the alteration of dry and wet season may have an effect on the eukaryotic species composition in the hair of sloths.

Despite the differing species compositions on sloth hair, the results (Fig. 2a) show that besides primary producers (27\% algae), there are also heterotrophic organisms (52\% ciliates, apicomplexans and dinoflagellates) as well as decomposers ( $8 \%$ fungi) in the fur, suggesting that sloth fur supports a versatile small-scale ecosystem. This was not seen in the environmental samples (Fig. $2 \mathrm{~b}$ ) in which $87 \%$ of the organisms are primary producers (algae or plants) or decomposers (fungi).

\section{Conclusions}

This is the first comparative survey of the algae and other organisms found in the fur of all six extant species of sloths, and the first study to use molecular methods to explore evolutionary relationships among the algae. We confirm that a great variety of eukaryotes live in sloth fur in addition to the various green algae. We also show the presence of an alga, attributable to at least three species of the genus Trichophilus, that has been found only in sloth hair, and thus apparently is passed directly from the mother to the offspring. That finding adds strong support to the idea that the relationship between sloths and at least one particular alga, Trichophilus spp., is a symbiotic one.

\section{Methods}

\section{Sample collection and morphological studies}

We examined 71 hair samples from 22 individuals of Choloepus hoffmanni, 2 individuals of $C$. didactylus, 10 individuals of Bradypus tridactylus, 17 individuals of $B$. variegatus, 12 individuals of $B$. pygmaeus and 8 individuals of $B$. torquatus. The sampled sloths came from French Guiana, Panama, Costa Rica and Brazil. The sampling was done in dry or wet season and details of collection sites, sloth species and dates are presented in the Additional file 1. A small tuft of sloth hair was sampled from a greenish patch, if the animal was visibly green or a darker patch if no greenish coloring was observed. The hair was removed with scissors and preserved in a plastic vial containing silica gel. Samples were stored in silica gel at ambient temperature until further processing, which usually varied from one to three months. All hair samples were studied with a light microscope. If green algae were visibly present they were photographed for further comparison and preserved samples were kept in silica gel for herbarium material. In addition to the sloth hair samples we collected environmental samples from 12 locations on Barro Colorado Island (Additional file 2). The samples were scraped from the surface of tree trunks, or in one case from the surface of a metal pole, from patches which were visibly green. The greenish material was scraped using a scalpel, stored in a plastic vial containing silica gel and stored as described above.

\section{DNA extraction, PCR, Cloning and Sequencing}

DNA was extracted with phenol-chloroform [17] and further purified using the High Pure PCR Template Preparation Kit (Roche), according to the manufacturers' instructions. A $1.5 \mathrm{~kb}$ fragment of the $18 \mathrm{~S}$ rRNA was amplified using the universal primers UNI7F and UNI1534R [18]. However, in some hair samples we were only able to get sequences from other eukaryotes but not from green algae, even though they were clearly visible under the microscope. Therefore, additional primers 501F (5' GGGTCTGGTTTTGAAATGAGG 3') and 1700R (5' CCGAAGTCTTCACCAGCACATC 3') were 
used to amplify a $1.2 \mathrm{~kb}$ fragment of the $18 \mathrm{~S}$ gene from the green algae. Alternatively a combination of universal and green algal specific primers was used to amplify the green algae present in the samples. A combination of primers 107F (5' CGAATGGCTCATTAAAT 3') and UNI1534R were used to amplify the green algae in the sample BT54_10, which was collected in Brazil.

The PCR amplification was done using Taq DNA polymerase (ABgene) in $25 \mu \mathrm{l}$ reactions. $0.6 \mu$ l Bovine Serum Albumin (BSA, Fermentas, $1 \mathrm{mg} / \mathrm{ml}$ ) was added into the $25 \mu \mathrm{l}$ PCR reaction to prevent potential inhibitors in the total DNA carried from hair samples to the PCR reactions. The fragments were amplified in a PCR cycle of initial denaturing of 3 minutes at $94^{\circ} \mathrm{C}$, followed by 30 cycles of 1 minute at $94^{\circ} \mathrm{C}, 1$ minute at $50^{\circ} \mathrm{C}$, 2 minutes at $72^{\circ} \mathrm{C}$ and a final extension of 5 minutes at $72^{\circ} \mathrm{C}$. Products were run on $1 \%$ agarose gel and the fragments of desired length were cloned using pGEM $^{\circ}-\mathrm{T}$ Easy Vector System II -cloning kit (A1380, Promega) according to the manufacturers' instructions. Positive colonies were picked with a toothpick, dipped into PCR reaction mixture with Taq DNA polymerase (ABgene) and PCR amplified using vector primers T7 (5' TAATACGACTCACTATAGGG 3') and SP6 (5' ATTTAGGTGACACTATAGAA 3').

The PCR products from the clone libraries were purified using Illustra GFX ${ }^{\text {su }}$ PCR DNA and Gel Band Purification Kit (GE Healthcare) or MultiScreen ${ }^{\circ}$ PCR $\mu 96$ (Millipore). They were sequenced using primers SP6 and T7 or primers used for PCR amplification (UNI7F, UNI1534R, 501F or 1700R) as well as with internal universal primers 384F (5' ACCACATCCAAGGAWGGCA $\left.3^{\prime}\right)$ or $18 \mathrm{~S} 384 \mathrm{~F}$ (5' GGCKACCACAUCCAAGGAWGGCA 3') designed for this study. The samples were loaded on an automated sequencer $3730 \times 1$ (Applied Biosystems) or ABI3130XL Genetic Analyzer (Applied Biosystems).

\section{Sequence alignment and phylogenetic analyses}

The 18S rRNA gene sequences obtained in this work were manually corrected using Chromas 2.31 (Technelysium, Pty Ltd.) sequence analysis software. Vector sequence was removed and all sequences shorter than $650 \mathrm{bp}$ were excluded from further analysis. The dataset of 426 sequences (hair samples) and 78 sequences (environmental samples) were analyzed using the BLAST network service [19] against $\mathrm{nr}$ database at NCBI and results were parsed for taxonomic information.

In order to obtain a reliable alignment for further analyses, 43 sequences of sloth hair that began at the 3' end of the $18 \mathrm{~S}$ gene were removed. For the remaining 383 sequences operational taxonomic units (taxa) were defined at $97 \%$ similarity (Additional file 3 ) from the MAFFT vs. 6 [20] aligned (1.53 gap opening penalty, 0.123 gap extension penalty) and Phylip version 3.6 [21] -Kimura 2-parameter corrected distance matrix using the furthest neighbor command of the DOTUR program [22]. Coverage [23] was calculated for the whole dataset by the following equation: $C=(1-n / N) * 100 \%$, where $C$ is the coverage percentage, $n$ is the number of taxa $(97 \%$ similarity) appearing only once, and $N$ is the number of all sequences in the library. The estimated number of taxa $\left(\mathrm{S}_{\mathrm{Chao1}}\right)$ and Shannon diversity index with $95 \%$ confidence intervals were calculated using DOTUR. Principal Coordinate Analysis followed by canonical analysis on PCO axes and calculation of canonical test statistic $\left(t_{2}\right)$ was performed with the program CAP $[24,25]$ using chi-square distance and visualized with SPSS 15 . The chi-square distance was chosen since it standardizes differences in scale and emphasizes changes in composition rather than changes in abundance. This was chosen because the abundance of sequences was derived from PCR amplification which is not a real abundance, but a compositional view. The program determined the appropriate number of dimensions $(m)$ included in the canonical analysis and identified the taxa that were responsible for multivariate patterns. The number of each $97 \%$ taxa was treated as one variable and a sloth species collected from one locality was treated as a sample.

The newly determined green algal $18 \mathrm{~S}$ rRNA gene sequences were compared to a broad selection of corresponding sequences from members of the Chlorophyta. The closest matching full $18 \mathrm{~S}$ rRNA gene sequence for each algal clone, as found from BLAST [19] searches, was also included. The selection of sequences was based on a phylogenetic tree comprising an expanded sample of more than 1500 rRNA gene sequences from the green algae which is available in the $18 \mathrm{~S}$ rRNA gene sequence database maintained in the ARB program [26]. This database was updated with all currently available 18S rRNA gene sequences from the Chlorophyta. Newly determined almost full sequences ( $>1600$ bp long) as well as partial sequences from clone libraries were added to the database using the parsimony interactive tool in ARB. The alignment was refined by comparing the sequences with their next relatives from the ARB database based on their pairing across a helix using secondary structure models as implemented in ARB. This program generates a MP tree from all sequences and all positions in the database as its reference tree, using a filter based on $50 \%$ base frequency across all species. A subset of these sequences comprising a total of 63 representatives of the green algal classes Ulvophyceae, Trebouxiophyceae and five prasinophytes (with prasinophyte sequence AF203402 as outgroup) was then 
downloaded from the ARB database for further analyses using the $50 \%$ base frequency filter. The final alignment of 68 taxa (23 algal sequences from sloth hair, 2 from tree bark) was 1690 nucleotides in length. Of the aligned sites, 419 were parsimony informative and an additional 185 were variable but not informative. An optimized maximum likelihood tree (see below) was then uploaded into ARB. To infer the phylogenetic positions of additional rDNA clones (almost full and partial sequences) which were not used for phylogeny construction were added to this tree using the parsimony interactive tool.

Maximum likelihood phylogenies were calculated using PAUP* version 4.0b10 [27] and GARLI v0.96 http://www.nescent.org/wg_garli[28] (Additional file 4 and Additional file 5). ModelTest 3.7 [29] used in conjunction with PAUP $4 \mathrm{~b} 10$ determined that the $\mathrm{TrN}+\mathrm{I}+\mathrm{G}$ model [30] provided the best fit to the data according the AIC criterion with estimations of nucleotide frequencies $(\mathrm{A}=0.254, \mathrm{C}=0.217, \mathrm{G}=0.281, \mathrm{~T}=0.248)$, a rate matrix with six different substitution types, assuming a heterogeneous rate of substitutions with a gamma distribution of variable sites (number of rate categories $=4$, shape parameter $=0.60$ ) and a proportion of invariable sites (pinvar) of 0.46 . The ML tree obtained in PAUP was used as input for three additional rounds of ML analyses to search for trees with smaller -ln likelihoods, but trees with better likelihood scores were not obtained. Bootstrap resampling was performed on the ML tree obtained in GARLI with 1000 replications. Bayesian phylogenetic analysis was performed with MrBayes version 3.1.2 [31,32] using the GTR $+\mathrm{I}+\mathrm{G}$ model (rate matrix with six different substitution types, number of rate categories $=4$, and with the nucleotide frequencies, shape parameter $\alpha$, and pinvar estimated from the data), four Markov chains and 2,000,000 generations sampling every 100 generations with the first $25 \%$ of the sampled trees discarded, leaving 15,000 trees. Posterior probabilities were then calculated from two independent runs using the $50 \%$ majority rule consensus of the kept trees. Minimum Evolution [33], neighborjoining [34] distance and Maximum Parsimony (MP) approaches were done in PAUP 4b10. ME distance trees were constructed with DNA distances set to maximum likelihood and a heuristic search procedure with 10 random input orders and TBR were employed to find the best tree. Best scoring trees were held at each step. NJ phylogenies were constructed in connection with the "HKY85 model" [35]. In MP analyses, the sites were weighted (RI over an interval of 1-1000). The heuristic search for the best tree was the same as in ME analyses. Bootstrap resampling was performed on $\mathrm{NJ}$ trees with 2000, for ME and MP with 1000 replications.
Additional file 1: Sloth sample collection details. Collection details of the sloth samples which sequence data was used in the study and the number of clones sequenced from each sample.

Additional file 2: Environmental sample collection details. Collection details of the environmental samples which sequence data was used in the study and the number of clones sequenced from each sample.

Additional file 3: Sequences belonging to a certain taxon with $\mathbf{9 7 \%}$ similarity. Sequences belonging to a certain taxon with $97 \%$ similarity. The number in the first column refers to numbers at the arrowheads in Fig. 3c.

Additional file 4: Ulvophycean green algae in Fig. 4. Additional clones originated from sloth hairs and tree bark which were positioned within the Ulvophyceae in the phylogenetic analyses of Fig. 4.

Additional file 5: Sequences of the clades that were shown compressed in Fig. 4. Sequences of the clades which were shown compressed in Fig. 4.

\section{Acknowledgements}

We are grateful to Roland Kays (New York State Museum) for his help, encouragement and advice at the start of the project. We also thank him for his help in sample collection. The following people helped us with searching for sloths, catching them or provided sloth hair samples: Ingrun Vogel (Association Kwata, French Guiana), Jennifer and Jeanine Licare (Organization Kids Saving the Rainforest, Costa Rica), Kirsi Pynnönen (Helsinki Zoo), Bernardo B. Dias, Bonifacio De León, Luis A. Dias, Christie Riehl and Marcus Martinez. Tatyana Darienko and Nataliya Rybalka performed microscopic analyses on many hair samples. We are very grateful for their help. The Museu de Biologia Mello Leitão and Instituto de Pesquisas da Mata Atlântica helped with logistics in collecting the samples in Brazil. The Brazilian sloth hair samples were exported with the permission number 0131864 BR and the samples from Panama were exported with Autoridad Nacional del Ambiente (ANAM) permits DNPN-01-2001 and SEX/A-73-06. This work was supported by the Linnean Society of London, the University of Helsinki Chancellors Travel Grants and Emil Aaltonen Foundation.

\section{Author details}

'Department of Environmental Sciences, P.O.Box 65, FIN-00014, University of Helsinki, Helsinki, Finland. ${ }^{2}$ Tvärminne Zoological Station, J.A. Palménin tie 260, FIN-10900 Hanko, Finland. ${ }^{3}$ Department of Food and Environmental Sciences, P.O. Box 66, FIN-00014, University of Helsinki, Helsinki, Finland. ${ }^{4}$ Max-Planck Institute for Ornithology, Schloß Möggingen, Schloßallee 2, 78315 Radolfzell, Germany. ${ }^{5}$ Smithsonian Tropical Research Institute, Apartado 0843-03092 Balboa, Ancon, Rep. Panama. ${ }^{6}$ Albrecht-von-HallerInstitut für Pflanzenwissenschaften, Abteilung Experimentelle Phykologie and Sammlung für Algenkulturen, Universität Göttingen, Untere Karspüle 2, 37073 Göttingen, Germany. 'Catholic University of Minas Gerais, Programa de pós-graduação em Zoologia de Vertebrados, Av. Dom José Gaspar 500, Prédio 41, Belo Horizonte, MG, CEP: 30.535-610, Brazil.

\section{Authors' contributions}

MS collected samples, carried out the molecular systematic work as well as drafted the manuscript. MM and TF performed the statistical and molecular phylogenetic analyses. DPF and JB conceived and designed the study. In addition, JB carried out molecular systematic work and coordinated the study. BV, AA and AGC participated in sample collection and the design of the study. In addition all authors have contributed on the manuscript drafting. All authors read and approved the final manuscript.

Received: 20 November 2009 Accepted: 30 March 2010 Published: 30 March 2010

\section{References}

1. Anderson RP, Handley CO Jr: A new species of three-toed sloth (Mammalia: Xenarthra) from Panama, with a review of the genus Bradypus. P Biol Soc Wash 2001, 114:1-33. 
2. Chiarello AG: Sloth Ecology, an overview of field studies. The Biology of the Xenarthra Gainesville: University Press of FloridaVizcaino SF, Loughry WJ 2008, 269-280.

3. Aiello A: Sloth hair: unanswered questions. The Evolution and Ecology of Armadillos, Sloths and Vermilinguas Washington, London: Smithsonian Institution PressMontgomery GG 1985, 213-218.

4. Wujek DE, Cocuzza JM: Morphology of Hair of Two- and Three- Toed Sloths (Edentata: Bradypodidae). Rev Biol Trop 1986, 34:243-246.

5. Britton SW: Form and function in the sloth. Q Rev Biol 1941, 16:13-34, 190207.

6. Thompson $\mathrm{RH}$ : Algae from the hair of the sloth Bradypus [abstract]. J Phycol 1972, 8(2b):8.

7. Wujek DE, Lincoln TA: Ultrastructure and Taxonomy of Oscillatoria pilicola, a New Species of Bluegreen Alga from Sloth Hair. Brenesia 1988, 29:1-6.

8. Weber-van Bosse A: Étude sur les algues parasites des Paresseux. Natuurk Verh Holl Maatsch Wetensch Haarlem III 1887, 5:10.

9. Wujek DE, Timpano P: Rufusia (Porphyridiales, Phragmonemataceae), a new red alga from sloth hair. Brenesia 1986, 25-26:163-68.

10. Rindi F, Mclvor L, Sherwood AR, Friedl T, Guiry MD, Sheath RG: Molecular phylogeny of the green algal order Prasiolales (Trebouxiophyceae, Chlorophyta). J Phycol 2007, 43:811-822.

11. Karsten U, Friedl T, Schumann R, Hoyer K, Lembcke S: Mycosporine-like amino acids and phylogenies in green algae: Prasiola and its relatives from the Trebouxiophyceae (Chlorophyta). J Phycol 2005, 41:557-566.

12. Printz H: Die Chaetophoralen der Binnengewässer. Eine systematische Übersicht. Hydrobiologia 24:1-376.

13. Montgomery GG, Sunquist ME: Habitat selection and use by two-toed and three-toed sloths. The Ecology of Arboreal Folivores Washington, DC: Smithsonian Institution PressMontgomery G 1978, 329-359.

14. Welcker $\mathrm{H}$ : Ueber die Entwicklung und den Bau der Haut und der Haare bei Bradypus, nebst Mittheilungen über eine im Inneren des

Faulthierhaares lebende Alge. Abhandl Naturforsch Ges Halle 1864, 9:17-72.

15. Delsuc F, Vizcaino SF, Douzery EJP: Influence of Tertiary paleoenvironmental changes on the diversification of South American mammals: a relaxed molecular clock study within xenarthrans. BMC Evol Biol 2004, 4:11.

16. Leigh EG Jr: Tropical Forest Ecology Oxford University Press. USA 1999.

17. Maggs CA, Ward BA: The genus Pikea (Dumontiaceae, Rhodophyta) in England and the North Pacific: comparative morphological, life history, and molecular studies. J Phycol 1996, 32:176-93.

18. Moon-van der Staay SY, De Wachter R, Vaulot D: Oceanic 18S rRNA gene sequences from picoplankton reveal unsuspected eukaryotic diversity. Nature 2001, 409:607-610.

19. Altschul SF, Gish W, Miller W, Myers EW, Lipman DJ: Basic local alignment search tool. J Mol Biol 1990, 215:403-410.

20. Katoh M, Kuma M: MAFFT: a novel method for rapid multiple sequence alignment based on fast Fourier transform. Nucleic Acids Res 2002, 30:3059-3066

21. Felsenstein J: PHYLIP (Phylogeny Inference Package) version 3.6 Distributed by the author. Department of Genome Sciences, University of Washington, Seattle 2004.

22. Schloss PD, Handelsman J: Introducing DOTUR, a computer program for defining operational taxonomic units and estimating species richness. Appl Environ Microbiol 2005, 71:1501-1506.

23. Good IJ: The population frequencies of species and the estimation of population parameters. Biometrika 1953, 40:237-264.

24. Anderson MJ, Robinson J: Generalized discriminant analysis based on distances. Aust N Z J Stat 2003, 45:301-318.

25. Anderson MJ, Willis TJ: Canonical analysis of principal coordinates: a useful method of constrained ordination for ecology. Ecology 2003, 84:511-525, 26.

26. Ludwig W, Strunk O, Westram R, (32 co-authors), et al: ARB: a software environment for sequence data. Nucleic Acids Res 2004, 32:1363-1371.

27. Swofford DL: PAUP*: Phylogenetic analysis using parsimony ( ${ }^{*}$ and other methods), version 4.0610 Sinauer Associates, Sunderland, Massachusetts 2001.

28. Zwickl DJ: Genetic algorithm approaches for the phylogenetic analysis of large biological sequence datasets under the maximum likelihood criterion. PhD thesis The University of Texas at Austin 2006

29. Posada D, Crandall KA: ModelTest: Testing the model of DNA substitution. Bioinformatics 1998, 14:817-818.
30. Tavaré S: Some probabilistic and statistical problems in the analysis of DNA sequences. Some mathematical questions in biology - DNA sequence analysis Am Math Soc Providence, RIMiura RM 1986, 57-86.

31. Huelsenbeck JP, Ronquist F: MrBayes: Bayesian inference of phylogenetic trees. Bioinformatics 2001, 17:754-755.

32. Ronquist F, Huelsenbeck JP: MRBAYES 3: Bayesian phylogenetic inference under mixed models. Bioinformatics 2003, 19:1572-74.

33. Rzhetsky A, Nei H: A simple method for estimating and testing minimum-evolution trees. Mol Biol Evol 1992, 9:945-67.

34. Saitou N, Nei M: The neighbor-joining method: a new method for reconstructing phylogenetic trees. Mol Biol Evol 1987, 4:406-25.

35. Hasegawa M, Kishino $H$, Yano K: Dating of the human-ape splitting by a molecular clock of mitochondrial DNA. J Mol Ecol 1985, 22:160-174.

doi:10.1186/1471-2148-10-86

Cite this article as: Suutari et al:: Molecular evidence for a diverse green algal community growing in the hair of sloths and a specific association with Trichophilus welckeri (Chlorophyta, Ulvophyceae). BMC Evolutionary Biology 2010 10:86.

\section{Submit your next manuscript to BioMed Central and take full advantage of:}

- Convenient online submission

- Thorough peer review

- No space constraints or color figure charges

- Immediate publication on acceptance

- Inclusion in PubMed, CAS, Scopus and Google Scholar

- Research which is freely available for redistribution

Submit your manuscript at www.biomedcentral.com/submit
C) Biomed Central 